Article

\title{
Vanillin Acrylate-Based Resins for Optical 3D Printing
}

\author{
Aukse Navaruckiene ${ }^{1}$, Edvinas Skliutas ${ }^{2}$, Sigita Kasetaite ${ }^{1}\left(\right.$, Sima Rekštyte ${ }^{2}$, \\ Vita Raudoniene ${ }^{3}$, Danguole Bridziuviene ${ }^{3}$, Mangirdas Malinauskas ${ }^{2} \mathbb{D}$ and \\ Jolita Ostrauskaite ${ }^{1, *}$
}

1 Department of Polymer Chemistry and Technology, Kaunas University of Technology, Radvilenu Rd. 19, LT-50254 Kaunas, Lithuania; aukse.navaruckiene@ktu.lt (A.N.); sigita.kasetaite@ktu.lt (S.K.)

2 Laser Research Center, Faculty of Physics, Vilnius University, Sauletekis Ave. 10, LT-10223 Vilnius, Lithuania; edvinas.skliutas@ff.vu.lt (E.S.); sima.rekstyte@ff.vu.lt (S.R.); mangirdas.malinauskas@ff.vu.lt (M.M.)

3 Biodeterioration Research Laboratory, Nature Research Center, Akademijos Str. 2, LT-08412 Vilnius, Lithuania; vita.raudoniene@gamtc.lt (V.R.); danguole.bridziuviene@gamtc.lt (D.B.)

* Correspondence: jolita.ostrauskaite@ktu.lt; Tel.: +370-37-300192

Received: 12 December 2019; Accepted: 7 February 2020; Published: 10 February 2020

\begin{abstract}
The investigation of biobased systems as photocurable resins for optical 3D printing has attracted great attention in recent years; therefore, novel vanillin acrylate-based resins were designed and investigated. Cross-linked polymers were prepared by radical photopolymerization of vanillin derivatives (vanillin dimethacrylate and vanillin diacrylate) using ethyl(2,4,6-trimethylbenzoyl)phenylphosphinate as photoinitiator. The changes of rheological properties were examined during the curing with ultraviolet/visible irradiation to detect the influences of solvent, photoinitiator, and vanillin derivative on cross-linking rate and network formation. Vanillin diacrylate-based polymers had higher values of yield of insoluble fraction, thermal stability, and better mechanical properties in comparison to vanillin dimethacrylate-based polymers. Moreover, the vanillin diacrylate polymer film showed a significant antimicrobial effect, only a bit weaker than that of chitosan film. Thermal and mechanical properties of vanillin acrylate-based polymers were comparable with those of commercial petroleum-derived materials used in optical 3D printing. Also, vanillin diacrylate proved to be well-suited for optical printing as was demonstrated by employing direct laser writing 3D lithography and microtransfer molding techniques.
\end{abstract}

Keywords: vanillin dimethacrylate; vanillin diacrylate; photopolymerization; optical 3D printing; direct laser writing; replica molding

\section{Introduction}

3D printing, also known as additive manufacturing, is a growing technology that has drawn increasing attention globally and has made a revolutionary impact on product fabrication in areas like medicine, the food industry, textiles, architecture, and construction [1]. Polymers are widely used in our everyday life due to their lightness, firmness, and relatively low cost; however, they are hard to form into intricate geometries. Additive manufacturing is the solution of creating complex geometries from plastics [2]. Several 3D printing technologies exist, allowing to create structures out of photo-curable resins. In stereolithography, resins are formed into 2D patterned layers [3], which become solid after exposing to UV light. By repeating this procedure, a 3D structure can be created layer by layer [4]. On the other hand, direct laser writing (DLW) 3D lithography can employ ultrashort pulses of focused VIS or near IR radiation instead of linearly absorbed UV light. This way a nonlinear light-matter interaction is achieved that confines the absorption and, subsequently, the cross-linking reaction in a small volume inside the resin, thus enabling full 3D (nonlayered) fabrication of structures with subwavelength feature sizes [5]. For 2D or quasi-3D structures, microtransfer molding (nanoimprint 
lithography) can be used. It employs the solidification of a resin (usually by UV light or thermally) inside the soft mold, thus replicating the master structure that was used to create the mold [6]. This technique is especially suitable in cases when many identical objects are required, as the same master structure can be used to make several molds, each suitable to create hundreds of replicas.

Advantages of photopolymerization are energy efficiency, high reaction rates, freedom from solvents [7], and the ability to photocure only the desired area of the resin [8]. Photopolymerization does not require any specific temperatures and can be performed at ambient conditions [9]. These features allow photopolymerization to be used in many engineering and manufacturing fields such as dental restoration, coatings, and 3D printing [10]. Radical photopolymerization is one of the most widely used photopolymerization processes. In this process, photoinitiator is used to generate radicals through cleavage and hydrogen abstraction reactions [11]. Acrylates and methacrylates are mostly used in free radical photopolymerization [12].

Vanillin is mostly obtained by extraction from the beans of vanilla orchids or by chemical modification of lignin, which is the second most prevalent biopolymer. Due to its aromatic structure, vanillin could replace widely used petro-based aromatic monomers [13]. Vanillin polymers exhibit re-processability and biodegradability under acid solution [14], as well as biodegradability in soil [15]. Recently, vanillin has been used to synthesize high-performance flame-retardant epoxy resins containing phosphorus [16]. Vanillin is one of the known natural compounds with antimicrobial properties [17]. It was determined that the polymeric films of vanillin derivatives also showed antimicrobial activity, which allow the use of vanillin-based polymers in food packing and medicine [18].

In this study, two commercially available vanillin derivatives, vanillin dimethacrylate (VDM) and vanillin diacrylate (VD), were tested in photocurable systems using ethyl(2,4,6-trimethylbenzoyl)phenylphosphinate (TPOL) as photoinitiator (Figure 1). TPOL was selected due to its high reaction rate and liquid form at room temperature [12]. TPOL is commonly used in optical 3D printing due to the photobleaching effect, which provides transparent coatings and allows coatings to cure in its lower layers [12]. The influence of the selected vanillin derivative, amount of photoinitiator, and the solvent's to photocross-linking rate and rigidity of resulting polymers were evaluated by real-time photorheometry. The yield of insoluble fraction, cross-linking density, and swelling value of selected polymers were calculated to confirm the cross-linked structure. Antimicrobial activity of the selected polymer film was determined and compared with that of chitosan and oxyethyl starch films. Thermal and mechanical properties were investigated and compared with those of other acrylate polymers based on natural phenolics, acrylated epoxidized soybean oil-based polymers, and commercial petroleum-derived materials used in optical 3D printing.<smiles>C=C(C)C(=O)OCc1ccc(OC(=O)C(=C)C)c(OC)c1</smiles>

VDM

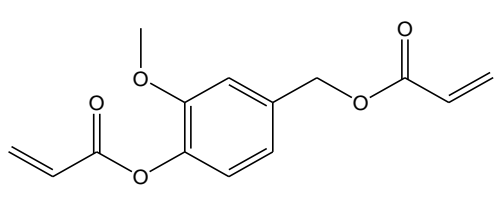

VD

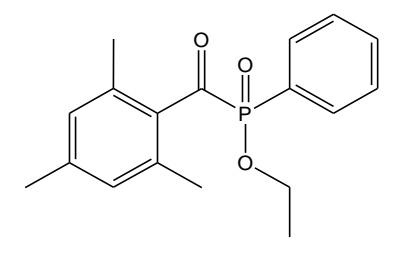

TPOL

Figure 1. Chemical structures of vanillin dimethacrylate (VDM), vanillin diacrylate (VD), and ethyl(2,4,6-trimethylbenzoyl)phenylphosphinate (TPOL).

\section{Materials and Methods}

\subsection{Materials}

Vanillin dimethacrylate (VDM) and vanillin diacrylate (VD) (both from Specific Polymers), ethyl(2,4,6-trimethylbenzoyl)phenylphosphinate (TPOL, Fluorochem), dichloromethane (DCM, Reachem Slovakia), and chitosan and hydroxyethyl starch (both from Sigma-Aldrich) were used 
as received. The Autodesk Standard Clear Prototyping Resin (PR48) was received from Autodesk. FormLabs Clear FL6PCL02 resin was received from FormLabs.

\subsection{Real-Time Photorheometry}

UV/Vis curing tests were performed with resins containing $1 \mathrm{~mol}$ of vanillin derivative (VDM or VD) and 1, 3, or 5 mol.\% of photoinitiator (TPOL) (Table 1) on a MCR302 rheometer (Anton Paar, Graz, Austria) equipped with the plate/plate measuring system. A minimal amount of DCM was used in some resins to dissolve solid components or for comparative investigations. The Peltier-controlled temperature chamber with the glass plate (diameter $38 \mathrm{~mm}$ ) and the top plate PP08 (diameter $8 \mathrm{~mm}$ ) was used. The measuring gap was set to $0.1 \mathrm{~mm}$. The samples were irradiated by UV/Vis light in a wavelength range of 250-450 $\mathrm{nm}$ through the glass plate of the temperature chamber using UV/Vis spot curing system OmniCure S2000 (Lumen Dynamics Group Inc., Mississauga, ON, Canada). The temperature was $24^{\circ} \mathrm{C}$. Shear mode with the frequency of $10 \mathrm{~Hz}$ and shear strain of $0.9 \%$ were used in all cases. Storage modulus $G^{\prime}$, loss modulus $G^{\prime \prime}$, loss factor $\tan \delta\left(\tan \delta=G^{\prime \prime} / G^{\prime}\right)$, and complex viscosity $\eta^{*}$ were recorded as a function of irradiation time. $G^{\prime}, G^{\prime \prime}$, and $\eta^{*}$ values were taken after $350 \mathrm{~s}$ of $\mathrm{UV} /$ Vis irradiation (Table 2). The gel point $t_{\text {gel }}$ was defined as a crossover point of $G^{\prime}$ and $G^{\prime \prime}$ modulus.

Table 1. Composition of the resins C1-C9.

\begin{tabular}{cccc}
\hline Resin & Vanillin Derivative & Solvent & $\begin{array}{c}\text { Amount of Photoinitiator } \\
\text { TPOL, mol.\% }\end{array}$ \\
C1 & VD & - & 1 \\
C2 & VD & DCM & 1 \\
C3 & VDM & DCM & 1 \\
C4 & VD & - & 3 \\
C5 & VD & DCM & 3 \\
C6 & VDM & DCM & 3 \\
C7 & VD & - & 5 \\
C8 & VD & DCM & 5 \\
C9 & VDM & DCM & 5 \\
\hline
\end{tabular}

Table 2. Rheological characteristics of the resins C1-C9.

\begin{tabular}{ccccc}
\hline Resin & $\begin{array}{c}\text { Storage Modulus } \\
\mathbf{G}^{\prime}, \mathbf{M P a}\end{array}$ & $\begin{array}{c}\text { Loss Modulus } \mathbf{G}^{\prime \prime}, \\
\mathbf{M P a}\end{array}$ & $\begin{array}{c}\text { Complex Viscosity } \\
\eta^{*}, \mathbf{M P a} \cdot \mathbf{s}\end{array}$ & Gel Point $^{\mathbf{a}} \boldsymbol{t}_{\text {gel }}, \mathbf{s}$ \\
\hline C1 & 7.35 & 6.34 & 0.15 & 14 \\
C2 & 13.40 & 2.35 & 0.22 & 20 \\
C3 & 13.00 & 1.65 & 0.21 & 6 \\
C4 & 18.10 & 2.70 & 0.29 & 6 \\
C5 & 11.30 & 1.64 & 0.18 & 5 \\
C6 & 18.20 & 2.94 & 0.29 & 10 \\
C7 & 13.30 & 5.78 & 0.23 & 6 \\
C8 & 14.50 & 2.02 & 0.23 & 6 \\
C9 & 19.80 & 3.36 & 0.32 & 6 \\
FormLabs Clear & 15.20 & 3.35 & 0.25 & 6 \\
FL6PCL02 & 21.40 & 4.19 & 0.35 & \\
PR48 & ${ }^{a}$ calculated from the UV/Vis irradiation onset.
\end{tabular}

\subsection{Preparation of Cross-Linked Polymer Specimens}

The mixtures containing $1 \mathrm{~mol}$ of vanillin derivative (VDM or VD), 1, 3, or $5 \mathrm{~mol} \%$ of TPOL, and, if needed, a minimal amount of DCM $(0.25 \mathrm{~mL}$ of DCM was used for $1 \mathrm{~g}$ of acrylate) were stirred at room temperature $\left(25^{\circ} \mathrm{C}\right)$ with a magnetic stirrer until homogenous phase was reached, then poured 
into a Teflon mold and cured for 1-4 min under a UV lamp (Helios Italquartz, model GR.E 500 W, Milan, Italy) with UV/Vis light at intensity of $310 \mathrm{~mW} / \mathrm{cm}^{2}$.

\subsection{Characterization Techniques}

Fourier transform infrared spectroscopy (FT-IR) spectra were recorded using a Spectrum BX II FT-IR spectrometer (Perkin Elmer, Llantrisant, UK). The reflection was measured during the test. The range of wavenumbers was $(650-4000) \mathrm{cm}^{-1}$.

Cross-linked polymers C3-C6 FT-IR ( $\left.\mathrm{cm}^{-1}\right)$ : 1714-1758, 1710-1732, 1730-1754 ( $\left.v, \mathrm{C}=\mathrm{O}\right), 1603$, 1603-1649, 1603-1647 ( $v, \mathrm{C}=\mathrm{C}), 737,801-802\left(v, \mathrm{CH}_{2}\right)$.

The yield of insoluble fraction was determined by Soxhlet extraction. Polymer samples of $0.5 \mathrm{~g}$ were extracted with acetone for $24 \mathrm{~h}$. After the extraction, the insoluble fractions were dried under vacuum until no changes of the weight were observed. The yield of insoluble fraction was calculated as a difference of the weight before extraction and after extraction and drying.

Differential scanning calorimetry (DSC) measurements were performed on a DSC 8500 apparatus (Perkin Elmer, Llantrisant, UK). The heating rate of $20^{\circ} \mathrm{C} / \mathrm{min}$ under nitrogen atmosphere $(50 \mathrm{~mL} / \mathrm{min})$ was used. The temperature ranged from -30 to $140^{\circ} \mathrm{C}$. A heating-cooling-heating cycle was used. Aluminum hermetic pans were used. The data were taken from the second heating curve.

Thermogravimetrical analysis (TGA) was performed on a TGA 4000 apparatus (Perkin Elmer, Llantrisant, UK). A heating rate of $20^{\circ} \mathrm{C} / \mathrm{min}$ under nitrogen atmosphere $(100 \mathrm{~mL} / \mathrm{min})$ was chosen, and the temperature ranged from 10 to $800^{\circ} \mathrm{C}$. Aluminum oxide pans were used.

The top pressure test was performed on a BDO-FBO.5TH material testing machine (Zwick/Roell, Kennesaw, GA, USA). In all cases, the compression force was $5 \mathrm{~N}$. The speed of compression was $50 \mathrm{~mm} / \mathrm{min}$. All tests were performed at $20^{\circ} \mathrm{C}$. The specimen was pressed with a cylindrical steel rod with a flat end of $8 \mathrm{~mm}$ diameter. The width of specimens was $30.0( \pm 0.00) \mathrm{mm}$ and the thickness of specimens was $2.2( \pm 0.2) \mathrm{mm}$. In order to avoid the expansion of specimens to the sides during the test, the specimens were placed in a Teflon mold of the same size. To obtain accurate results, 10 tests for each specimen were made. The compression modulus was calculated by the following equation:

$$
E_{c}=\frac{F \cdot l_{0}}{S \cdot \Delta l}
$$

where $E_{c}$ is a compression modulus (MPa); $S$ is a surface area of specimen $\left(\mathrm{mm}^{2}\right) ; F$ is a force $(\mathrm{N}) ; \Delta l$ is the difference of an initial thickness of specimen and thickness of a loaded specimen (mm); and $l_{0}$ is an initial thickness of specimen (mm).

The bending test was performed on RSA-G2 Solids Analyzer (TA Instruments, New Castle, Delaware, USA). The thickness of specimens was $1.7( \pm 0.1) \mathrm{mm}$, the width was $5.00( \pm 0.00) \mathrm{mm}$, and the length was $40.00( \pm 0.00) \mathrm{mm}$. Tests were carried out at $20^{\circ} \mathrm{C}$. The speed of bending was $0.1 \mathrm{~mm} / \mathrm{s}$. Three-point contact bending geometry with a $25 \mathrm{~mm}$ gap between end contacts was used.

Bending modulus was calculated using the following equation:

$$
\delta=\frac{3 \cdot F \cdot L}{2 \cdot w \cdot d^{2}}
$$

where $\delta$ is the bending modulus (Pa); $F$ is the maximum force applied to the specimen $(\mathrm{N}) ; L$ is the length of the specimen $(\mathrm{m}) ; w$ is the width of the specimen $(\mathrm{m})$; and $d$ is the thickness of the specimen (m) [19].

The swelling value of the cross-linked polymer specimens was obtained by measuring the volume of specimens swollen in chloroform and toluene at $25^{\circ} \mathrm{C}$. The polymer film specimens of $15( \pm 0.1) \mathrm{mm}$ length, $5( \pm 0.00) \mathrm{mm}$ width, and $0.5( \pm 0.05) \mathrm{mm}$ thickness were used. A glassy container comprised two spherical parts of $50 \mathrm{~mL}$ joined by a tube graduated with the accuracy of $0.02 \mathrm{~mL}$ was used. One spherical part was separated from the graduated tube by a liquid-permeable partition. This spherical part was fitted with the neck closed by a stopper. The swelling agent was poured, and the sample 
was placed in through this neck. The initial volume of the polymer film was measured before placing into the measuring container. The measuring container was kept in such position that a sample was immersed in the swelling agent during the test and turned in such position that the liquid leaked to another side of the container at every $5 \mathrm{~min}$. The change of the volume of the swelling agent was measured. The swelling value was calculated by the following equation:

$$
\alpha=\frac{V-V_{0}}{V_{0}} \cdot 100
$$

where $\alpha$ is a swelling value (\%); $V$ is a volume of swollen specimen $(\mathrm{mL})$; and $V_{0}$ is an initial volume of specimen $(\mathrm{mL})$.

The antimicrobial activity of the polymers was estimated quantitatively by inoculating specimens with microbial suspension. The test microorganisms were Gram-negative bacterium Escherichia coli ATCC 25,922 (E. coli) and Gram-positive bacterium Staphylococcus aureus ATCC 29,213 (S. aureus). The concentration of inoculum suspension was assessed with a spectrophotometer (Evolution 60S, Thermo Fisher Scientific, Waltham, MA, USA) and then corrected by seeding the suspension on Mueller Hinton agar (MHA). The final inoculum concentration of E. coli was $7 \times 10^{5}$ and $8 \times 10^{5} \mathrm{CFU} / \mathrm{mL}$ of S. aureus. The films of chitosan and hydroxyethyl starch prepared by casting from aqueous solutions were used for comparison. The testing specimens of C4, chitosan, and hydroxyethyl starch in dimensions of $10 \times 10 \mathrm{~mm}$ were placed into sterile Petri dishes of $50 \mathrm{~mm}$ diameter, inoculated with $10 \mu \mathrm{L}$ of prepared bacterial suspension, and incubated in humid chambers at $(35 \pm 2){ }^{\circ} \mathrm{C}$. After 2,6 , and $24 \mathrm{~h}$ the specimens were washed with $2 \mathrm{~mL}$ of sterile $0.85 \%$ saline, and serial dilutions of culture suspensions were sown on MHA in Petri dishes. The dishes with bacteria were incubated for $48 \mathrm{~h}$ at $(35 \pm 2)^{\circ} \mathrm{C}$. After incubation, colony numbers were counted, and percent reduction was calculated by the following equation: $(a-b) / a \times 100 \%$, where $a$ is a concentration of colony forming units (CFU/mL) in inoculum; and $b$ is a mean of recovered bacteria $(\mathrm{CFU} / \mathrm{mL})$ on specimens from triplicate after incubation.

\subsection{Optical Micro-Fabrication Techniques}

Two types of optical printing techniques were used to produce 3D objects out of custom made photocross-linkable resins. At first, direct laser writing (DLW) 3D lithography experiments were conducted employing a Pharos laser $(515 \mathrm{~nm}, 300 \mathrm{fs}, 200 \mathrm{kHz}$, Light Conversion Ltd., Vilnius, Lithuania), $20 \times \mathrm{NA}=0.8$ and $63 \times \mathrm{NA}=1.4$ objectives, and combined movement of the linear stages and galvano-scanners. The setup is shown in Figure 2a, and its detailed description can be found in a previous publication [20]. The goal was to figure out if the resins were suitable for ultrafast laser pulse initiated 3D polymerization. Woodpile structures were chosen as test objects. Their 3D model consisted of two layers of 2D gratings, connected by vertical columns $20 \mu \mathrm{m}$ high. The gratings comprised orthogonal sets of logs $15 \mu \mathrm{m}$ wide and $75 \mu \mathrm{m}$ long with a $15 \mu \mathrm{m}$ gap between them, resulting in a $30 \mu \mathrm{m}$ period of the structure. Each log was fabricated by performing multiple parallel scans, and the number depended on the distance $d_{x y}$ between them. $d_{x y}$ was set to 0.25 and $0.5 \mu \mathrm{m}$. Optimal exposure parameters were determined by varying the laser power $(P)$, which corresponded to the light intensity $(I)$ at the sample and scanning velocity $(v)$. During the fabrication, the resin was placed on a glass substrate through which it was irradiated by the laser beam. After the exposure, the samples were developed in dichloromethane for $30 \mathrm{~min}$, removing the uncured resin and leaving only the produced structures on the substrate.

Secondly, a microtransfer molding ( $\mu \mathrm{TM}$ ) technique, also known as nanoimprint lithography, was employed [21]. Steps involved in making the replica are depicted in Figure 2b. First, a master structure was fabricated out of acrylated epoxidized soybean oil (AESO) by DLW. Polydimethylsiloxane (PDMS) was poured over this structure and thermally cured at $100{ }^{\circ} \mathrm{C}$ for $1 \mathrm{~h}$, thus creating a soft mold (stamp). It was then used to make a replica out of $\mathbf{C} 4$ resin. The chosen structure was a 3D sculpture of Marvin - a SLT model, used as a benchmark sample for the material testing in the 3D 
printing community. A UV diode emitting $365 \mathrm{~nm}$ wavelength light (CS2010, Thorlabs, Newton, NJ, USA) was used to cure the $\mathbf{C} 4$ resin and obtain the replica.

The fabricated structures were characterized using scanning electron microscopes (SEM, Hitachi TM-1000, Tokyo, Japan and Prisma E, Eindhoven, The Netherlands).

(a)

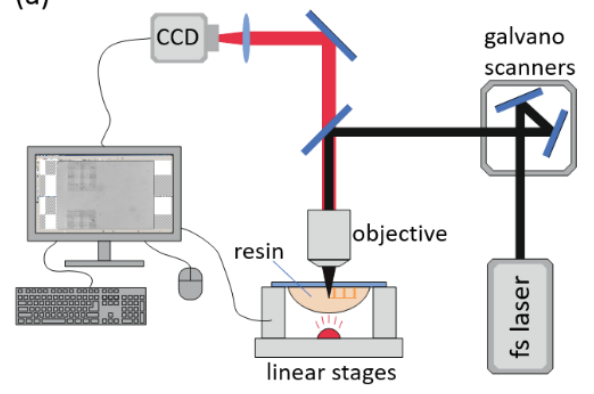

(b)

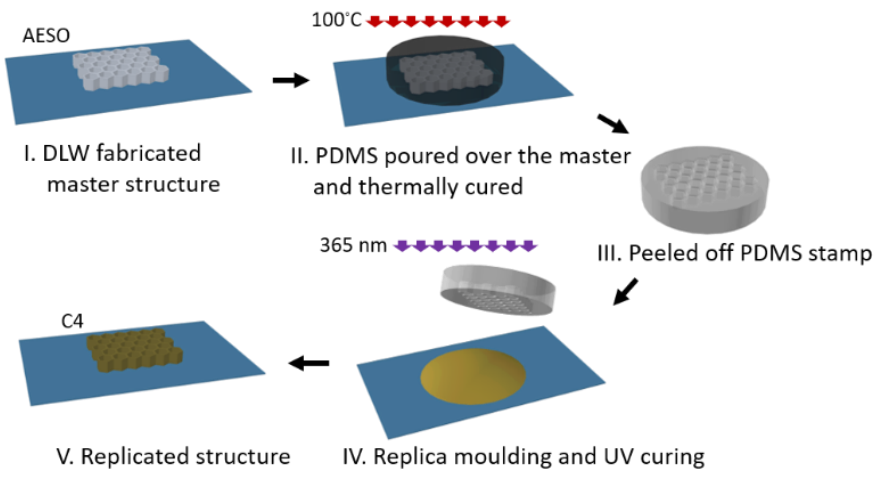

Figure 2. (a) Optical setup for direct laser writing (DLW) 3D lithography. (b) Steps of making the replica by the microtransfer molding $(\mu \mathrm{TM})$ technique.

\section{Results}

\subsection{Monitoring of Photocross-Linking Kinetics by Real-Time Photorheometry}

The photopolymerization of vanillin acrylate-based (VD and VDM) resins with various concentrations of TPOL as photoinitiator was studied by real-time photorheometry. As an example, Figure 3 shows the evolution of storage modulus $G^{\prime}$, loss modulus $G^{\prime \prime}$, loss factor tan $\delta$, and complex viscosity $\eta^{*}$ of the VDM-based resin $\mathbf{C} \mathbf{9}$ during UV/Vis irradiation. The cross-linking process began when the values of $G^{\prime}, G^{\prime \prime}$, and $\eta^{*}$ started to increase. The gel point $\left(t_{g e l}\right)$ (defined as $\left.G^{\prime}=G^{\prime \prime}\right)$ [22] of resin C9 was reached after $6 \mathrm{~s}$ from UV/Vis irradiation onset. As irradation of the resin proceeded with time, the values of $G^{\prime}, G^{\prime \prime}$ modulus, and $\eta^{*}$ continued to increase due to gel aging and settling down into a steady-state, indicating the end of the cross-linking process. All vanillin acrylate-based resins showed similar behaviours. Real-time photorheometry data of all resins are summarized in Table 2.

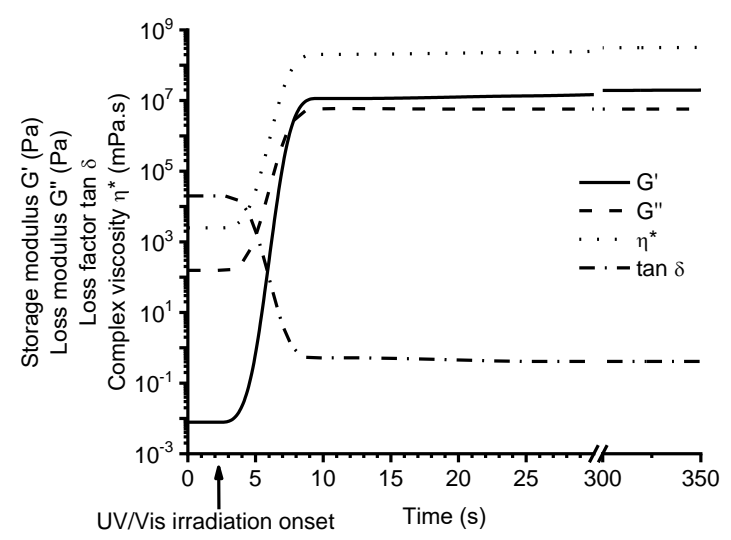

Figure 3. Dependencies of storage modulus $G^{\prime}$, loss modulus $G^{\prime \prime}$, loss factor tan $\delta$, and complex viscosity $\eta^{*}$ of resin $\mathrm{C} 9$ on irradiation time, at $24{ }^{\circ} \mathrm{C}$.

As the storage modulus $G^{\prime}$ characterizes the rigidity of the formed thermosetting polymers [23], the dependencies of $G^{\prime}$ on irradiation time of the resins with 1,3, and 5 mol.\% of TPOL are shown in Figure 4a. Comparing the shape of the $G^{\prime}$ curves of the resins with different concentrations of photoinitiator, the fastest photocross-linking and the highest final rigidity were demonstrated by resin 
C4 with 3 mol.\% of TPOL in the VD-based resins without solvent series $(\mathbf{C 1}, \mathbf{C 4}$, and $\mathbf{C 7})$. The presence of solvent had a higher influence on the photocross-linking rate than the concentration of photoinitiator. In VD-based resins with solvent series $(\mathbf{C} 2, \mathbf{C} 5$, and $\mathbf{C 8})$, the photocross-linking rates of two resins with 3 mol. $\%$ and 5 mol.\% of TPOL (C5 and C8 respectively) were very similar and faster than that of resin C2, although a more rigid polymer was obtained from resin C8. In VDM-based resins with solvent series (C3, C6, and C9), the photocross-linking rate did not depend on the concentration of TPOL, although a more rigid polymer was obtained from resin C9 with 5 mol.\% of TPOL. Comparing the gel points $\left(t_{g e l}\right)$ of the resins (Table 2), the $t_{\text {gel }}$ was reached the fastest when $3 \mathrm{~mol} \%$ of the TPOL was used in the case of all resin series. When a higher amount of photoinitiator was used, the effectiveness of photocross-linking was reduced due to the rapid photocross-linking of the surface layer, which reduced light penetration into the deeper layers of the material [24]. The addition of the solvent into the resin slowed down the photocross-linking process, and less-rigid polymers were obtained. For example, the resin $\mathbf{C} 4$ without solvent reached the gel point after $6 \mathrm{~s}$ and a rigidity of $18.10 \mathrm{MPa}$ was obtained, while resin $\mathrm{C} 5$ reached the gel point only after $12 \mathrm{~s}$ and obtained a rigidity of $11.30 \mathrm{MPa}$ (Table 2). This could be due to the solvent action as a chain transfer agent which slows down the photocross-linking process [25]. The photocross-linking of all VDM-based resins (C3, C6, and C9) was faster compared to all VD-based resins (C1, C2 $, \mathbf{C 4}, \mathbf{C} 5, \mathbf{C} 7$, and C8), although the acrylate group was earlier described as more active than the methacrylate group [26]. This could be due to the darker color of VD-based resins compared with VDM-based resins that could cause a slower polymerization process by making it harder for the light to reach and cure the deeper layers of the resins [27].

(a)

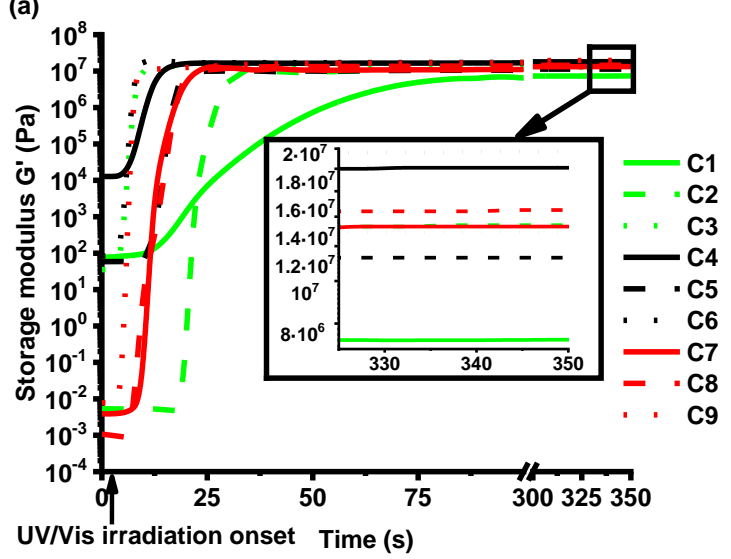

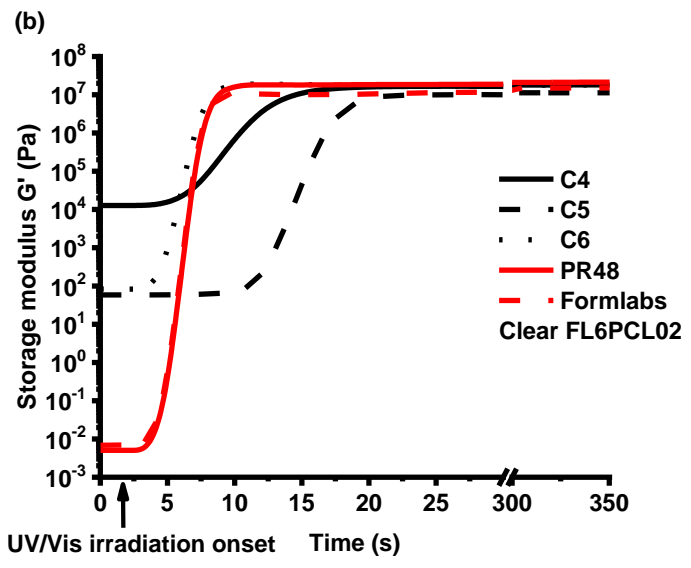

Figure 4. (a) Dependencies of storage modulus $G^{\prime}$ of the resins $\mathbf{C 1}-\mathbf{C} 9$ on irradiation time. Concentration of TPOL in the resins: green curves-1 mol.\%, black curves-3 mol.\%, red curves-5 mol.\%. (b) Dependencies of storage modulus G' of the resins C4-C6, FormLabs Clear FL6PCL02 and PR48 on irradiation time, at $24{ }^{\circ} \mathrm{C}$.

The series of resins with $3 \mathrm{~mol} \%$ of TPOL $(\mathbf{C 4}, \mathbf{C} 5$, and $\mathbf{C 6})$ were selected for further investigations according to the photocross-linking rate and polymer rigidity. These resins were compared with commercial acrylate resins for optical 3D printing, FormLabs Clear FL6PCL02 and PR48 (Figure 4b). Both commercial resins demonstrated similar photocross-linking rates (both $t_{\text {gel }}=6 \mathrm{~s}$ ) as resin $\mathrm{C} 4$ $\left(t_{\text {gel }}=6 \mathrm{~s}\right)\left(\right.$ Table 2). However, resin $\mathbf{C 6}$ demonstrated a slightly higher photocross-linking rate $\left(t_{\text {gel }}=5 \mathrm{~s}\right)$ than commercial resins. Moreover, the rigidity of resins $\mathbf{C} 4\left(G^{\prime}=18.10 \mathrm{MPa}\right)$ and $\mathbf{C 6}\left(G^{\prime}=18.20 \mathrm{MPa}\right)$ was slightly higher than that of FormLabs Clear FL6PCL02 $\left(G^{\prime}=15.20 \mathrm{MPa}\right)$, but less than that of PR48 ( $\left.G^{\prime}=21.40 \mathrm{MPa}\right)$. Resin C5 demonstrated poor behavior compared with commercial resins. The photocross-linking was slower $\left(t_{g e l}=12 \mathrm{~s}\right)$ and the rigidity was the lowest $\left(G^{\prime}=18.10 \mathrm{MPa}\right)$ from all the selected resins $\mathbf{C 4}, \mathbf{C 6}$, and commercial resins (Table 2). 


\subsection{Characterization of Photocross-Linked Polymer Structure}

The chemical structure of the vanillin-based polymers was identified by FT-IR spectroscopy. The signals of $C=C$ group, which were present at $1607 \mathrm{~cm}^{-1}$, and $C=O$ group, which were present at $1730 \mathrm{~cm}^{-1}$, in the FT-IR spectra of VDM and VD were reduced in the polymer spectra. The large increase of C-C group signal was detected at $1128-1131 \mathrm{~cm}^{-1}$, which shows the formation of polymer. As an example, the FT-IR spectra of VD and the cross-linked polymers C4 and C5 are presented in Figure 5.

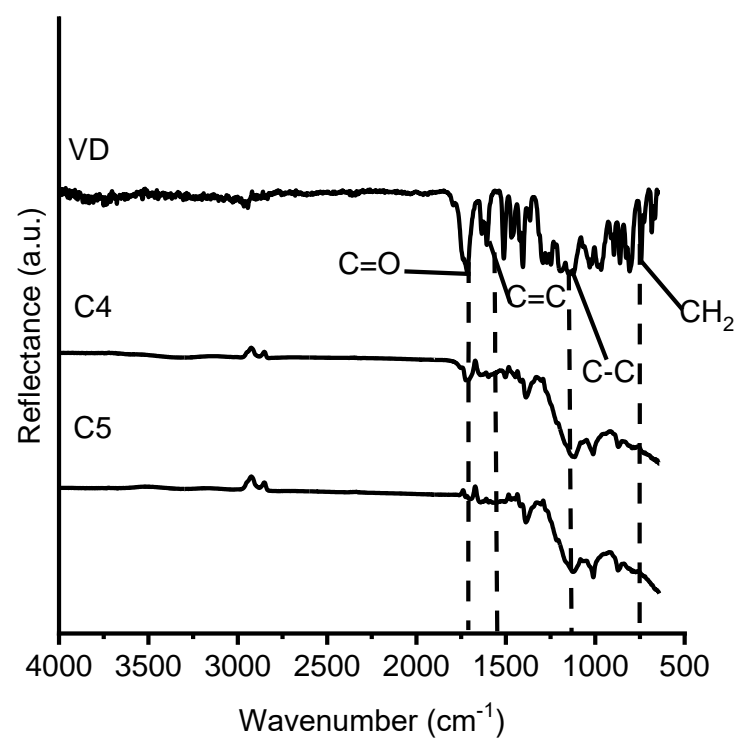

Figure 5. FT-IR spectra of VD and the cross-linked polymers C4 and C5.

To confirm the formed cross-linked structure of polymers, Soxhlet extraction was performed. The highest value of the yield of insoluble fraction was obtained for polymer $\mathbf{C 4}$, for which synthesis of VD was used without addition of DCM in comparison to polymer C5 ( $96 \%$ in comparison to $77 \%$ ) (Table 3). Swelling tests are of great importance to characterize the network structure. The higher swelling values showed that longer chains between the cross-linking points were formed in the polymer. Both $\mathrm{C} 4$ and C5 are vanillin diacrylate-based polymers; the only difference is that a small amount of DCM was used in the reaction mixture of $\mathrm{C} 5$, which resulted in the formation of the lower yield of insoluble fraction (Table 3) and the lower crosslinking density confirmed by the higher swelling values of polymer C5 (Figure 6, Table 3). C6 is vanillin dimethacrylate-based polymer in which preparation of a small amount of DCM was used; thus, higher swelling values were obtained in chloroform. Some other factors such as the polymer-solvent interaction can affect swelling properties as well. Vanillin dimethacrylate is soluble in chloroform and insoluble in toluene. The poor interaction of vanillin dimethacrylate-based polymer chains with toluene was the reason why the swelling of polymer C6 in toluene was worse than that in chloroform (Figure 6).

Table 3. Characteristics of the cross-linked vanillin-based polymers.

\begin{tabular}{cccc}
\hline Polymer & $\begin{array}{c}\text { Yield of Insoluble } \\
\text { Fraction, } \%\end{array}$ & $\begin{array}{c}\text { Swelling Value in } \\
\text { Chloroform, \% }\end{array}$ & $\begin{array}{c}\text { Swelling Value in } \\
\text { Toluene, } \%\end{array}$ \\
\hline C4 & 96 & $49.22 \pm 0.06$ & $48.62 \pm 0.06$ \\
C5 & 77 & $97.83 \pm 0.06$ & $96.85 \pm 0.06$ \\
C6 & 89 & $104.21 \pm 0.06$ & $54.72 \pm 0.06$ \\
\hline
\end{tabular}


(a)

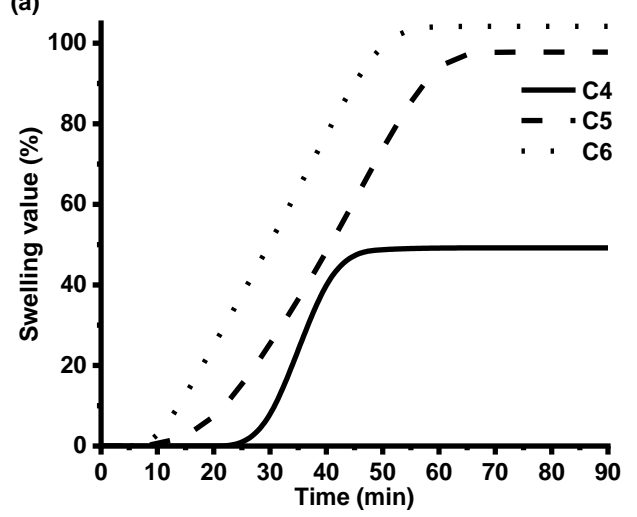

(b)

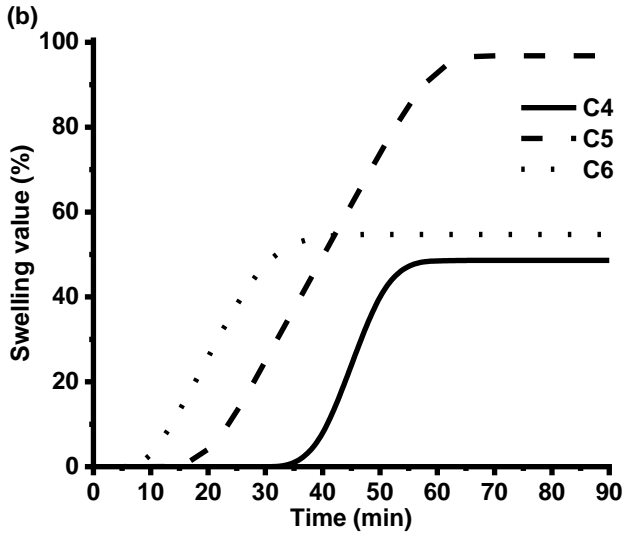

Figure 6. The swelling values of polymers C4-C6 in chloroform (a) and toluene solvent (b)

\subsection{Thermal Properties of Photocross-Linked Polymers}

DSC and TGA were used to study the thermal characteristics of the photocross-linked polymers C4-C6. Synthesized polymers are amorphous materials; therefore, only a glass transition was obtained in DSC curves (Figure 7a). The glass transition temperatures $\left(\mathrm{T}_{\mathrm{g}}\right)$ of polymers $\mathbf{C} \mathbf{4}$ and $\mathbf{C} \mathbf{6}$ were very similar ( 87 and $86^{\circ} \mathrm{C}$, respectively) and depended on the cross-linking density and the yield of insoluble fraction. A lower glass transition temperature was observed for polymer $\mathbf{C} 5\left(63{ }^{\circ} \mathrm{C}\right)$, with the lowest cross-linking density determined from the swelling test results. The glass transition temperatures of obtained polymers were similar to the acrylate resins based on natural phenolics, presented as candidate materials for stereolithography $\left(79^{\circ} \mathrm{C}\right)$ [28].
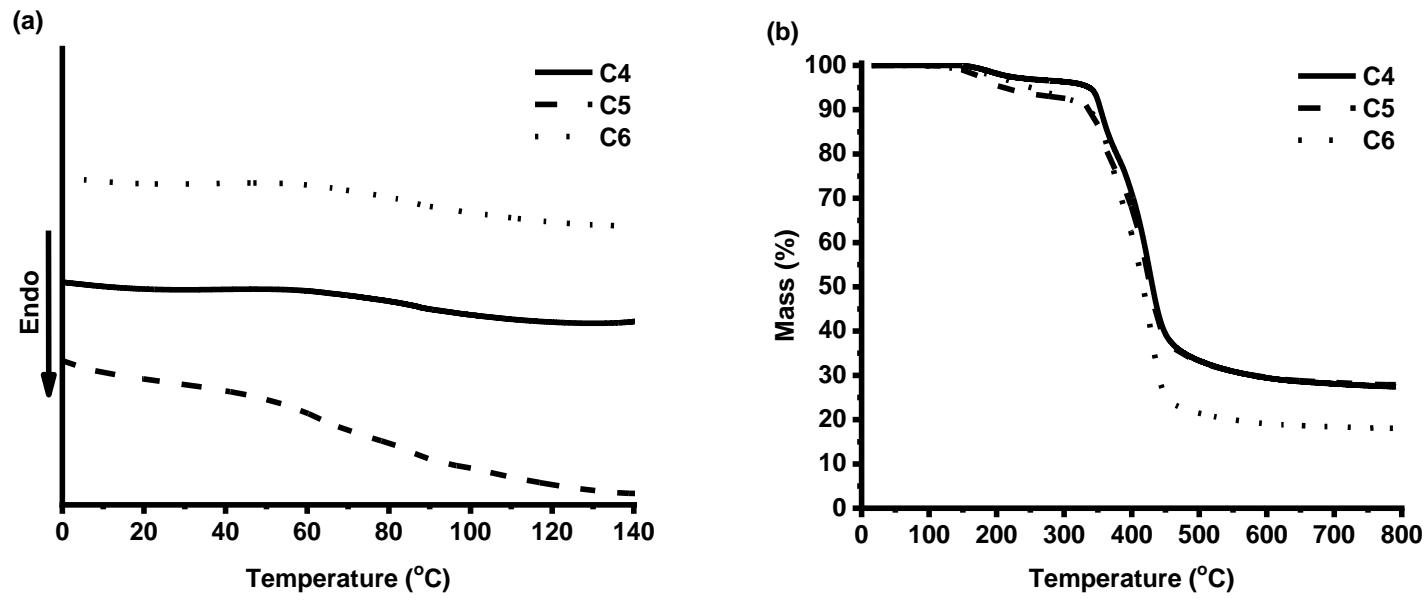

Figure 7. DSC thermograms (a) and thermogravimetric curves (b) of cross-linked polymers C4-C6.

Thermal decomposition of the synthesized polymers occurred in two steps (Figure $7 \mathrm{~b}$ ). The first step in the TGA curves can be explained by the presence of the branched or linear macromolecules. The temperature of $10 \%$ weight loss $\left(T_{\text {dec. }}-10 \%\right)$ of the VD-based polymer $\mathbf{C} 4\left(350{ }^{\circ} \mathrm{C}\right)$ was higher than that of the VD-based polymer $\mathbf{C} 5$ prepared using DCM $\left(330^{\circ} \mathrm{C}\right)$ and the VDM-based polymer $\mathbf{C} 6\left(340^{\circ} \mathrm{C}\right)$. Higher $T_{\text {dec.-10\% }}$ correlated with the higher yield of insoluble fraction and cross-linking density. The temperature of $10 \%$ weight loss of obtained polymers was similar or even slightly higher than that of some acrylated epoxidized soybean oil-based polymers $\left(297-356^{\circ} \mathrm{C}\right)$ tested in $3 \mathrm{D}$ printing [20].

\subsection{Mechanical Properties of Photocross-Linked Polymers}

Only resin $\mathrm{C} 4$ was suitable for the preparation of the specimens for bending and top pressure tests because the specimens of resins $\mathbf{C} 5$ and $\mathbf{C 6}$ cracked during the photocross-linking process, and it was 
impossible to make uniform specimens for these tests. To improve the mechanical properties of these polymers, addition of reactive diluents will be carried out in further studies. Commercial photoresins PR48 and FormLabs Clear FL6PCL02 were tested in the same conditions to compare their mechanical characteristics with those of polymer C4. The mechanical testing results are summarized in Table 4 . All polymers demonstrated low deformation during compression tests. Polymer C4 demonstrated a lower compression modulus than that of the polymers prepared from the commercial resins PR48 and FormLabs Clear FL6PCL02, but a much higher compression modulus than the acrylated epoxidized soybean oil based polymers $(0.19-0.66 \mathrm{~Pa})$ tested in 3D printing [20]. The specimens of all polymers did not break during the bending test. Very similar 30\% specimen bending forces and bending modulus were obtained for polymers C4 and PR48. The specimen prepared from FormLabs Clear FL6PCL02 demonstrated a lower $30 \%$ specimen bending force and bending modulus.

Table 4. Mechanical characteristics of the cross-linked vanillin-based polymers.

\begin{tabular}{ccccc}
\hline Polymer & $\begin{array}{c}\text { Deformation } \\
\text { during } \\
\text { Compression, } \%\end{array}$ & $\begin{array}{c}\text { Compression } \\
\text { Modulus, MPa }\end{array}$ & $\begin{array}{c}\text { Force of Specimen } \\
\text { Bend of } \mathbf{3 0} \% \mathbf{N}\end{array}$ & $\begin{array}{c}\text { Bending Modulus, } \\
\mathbf{M P a}\end{array}$ \\
\hline C4 & $4.95 \pm 0.02$ & $2.01 \pm 0.02$ & $3.65 \pm 0.04$ & $9.47 \pm 0.04$ \\
PR48 & $1.79 \pm 0.02$ & $5.56 \pm 0.02$ & $3.39 \pm 0.07$ & $8.80 \pm 0.07$ \\
$\begin{array}{c}\text { FormLabs Clear } \\
\text { FL6PCL02 }\end{array}$ & $1.39 \pm 0.02$ & $7.17 \pm 0.02$ & $0.42 \pm 0.02$ & $1.09 \pm 0.02$ \\
\hline
\end{tabular}

According to the results, resin C4 was selected for further testing by optical micro-fabrication techniques, and the testing of antimicrobial activity was carried out.

\subsection{Antimicrobial Activity}

The testing of antimicrobial activity was performed for polymer $\mathbf{C 4}$ and two reference polymer films of chitosan and hydroxyethyl starch. The results of antibacterial activity testing demonstrated that polymer C4 killed 99\% of both Gram-negative E. coli and Gram-positive S. aureus after $6 \mathrm{~h}$ of contact time, and after $24 \mathrm{~h}$, all bacteria on this film were lifeless (Figure 8). Bacteria on the hydroxyethyl starch film, having no antibacterial activity, even began to propagate after 2 contact hours. In comparison with chitosan, which is known to have a very strong antibacterial activity [29], polymer C4 showed only a bit weaker activity. In our experiment, bacteria on the chitosan film were killed completely after 2 contact hours. These results are in agreement with other studies indicating significant antimicrobial effects of vanillin and vanillin incorporation into complex compounds [18,30,31].

(a)

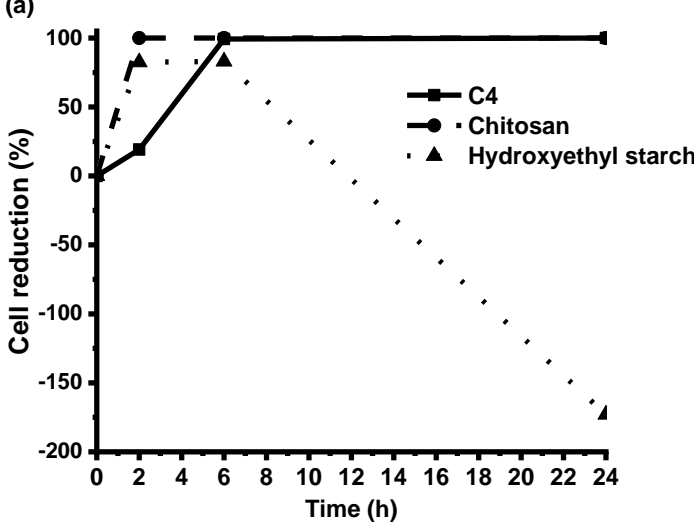

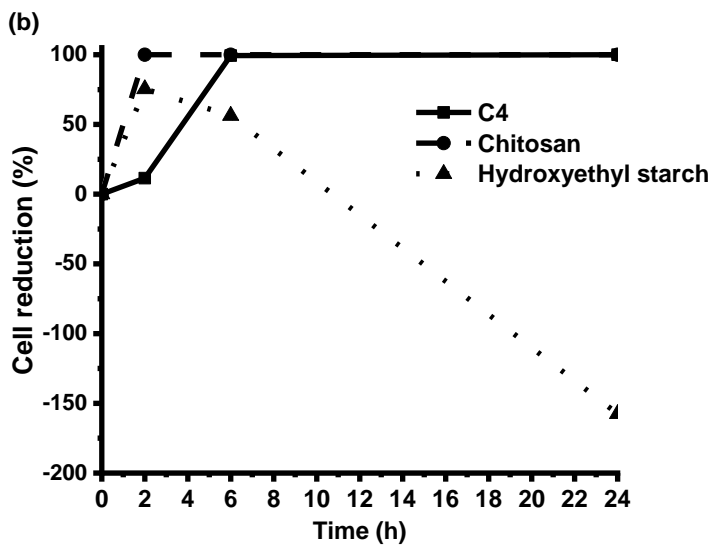

Figure 8. The reduction of E. coli (a) and S. aureus (b) cells during $24 \mathrm{~h}$ of contact time with specimens of polymer C4, chitosan, and hydroxyethyl starch. 


\subsection{Characterization of Optically Printed Structures}

A test to assess the optimal fabrication parameters was performed, and the capability to produce 3D microporous woodpile structures out of the resin C4 via DLW was demonstrated. An array of $75 \times 75 \mu \mathrm{m}^{2}$ woodpiles is shown in Figure $9 \mathrm{a}, \mathrm{b}$. Manufacturing parameters and focusing conditions are provided in the caption of Figure 9.

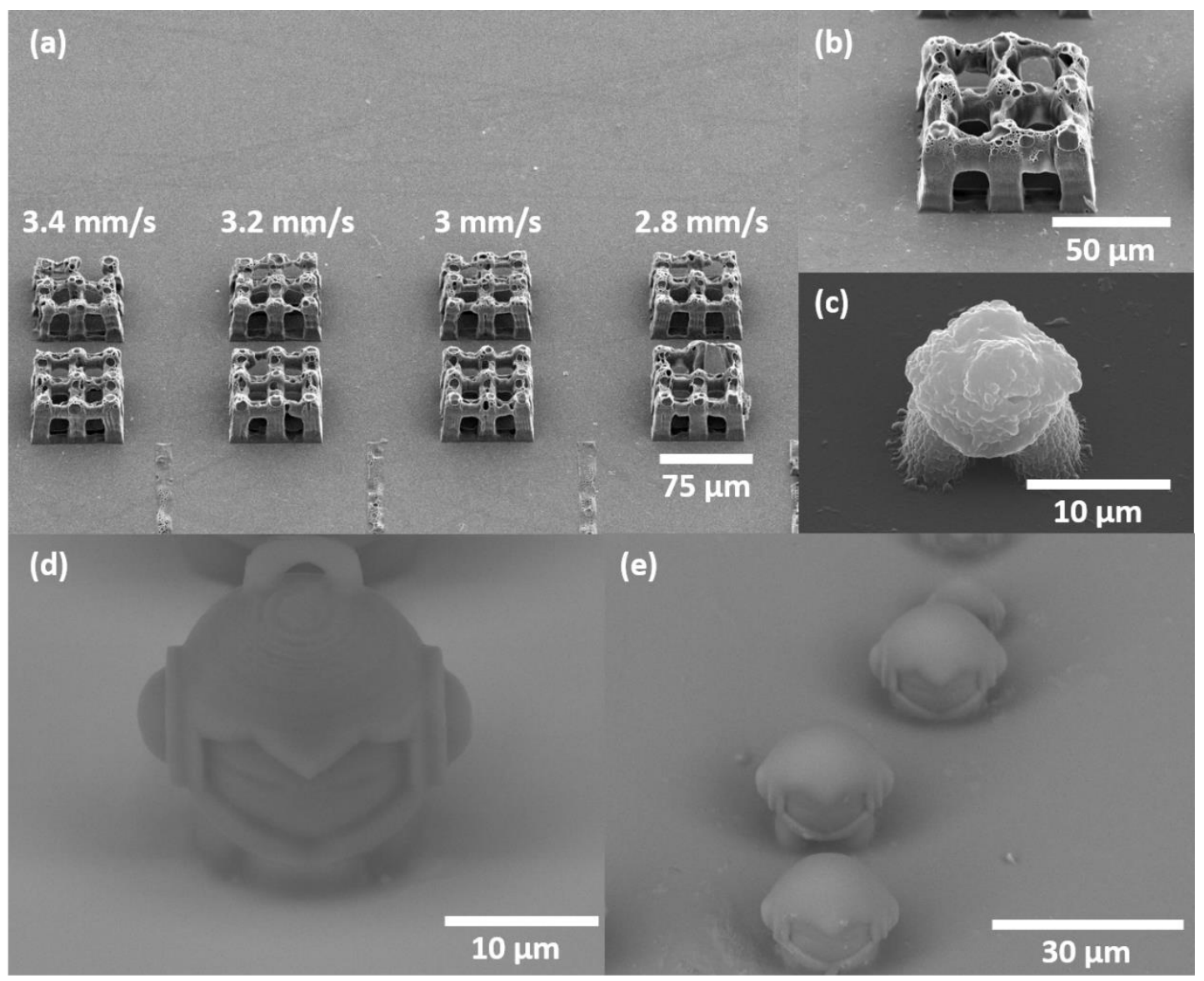

Figure 9. (a) Array of the $75 \times 75 \mu \mathrm{m}^{2}$ size woodpile structures out of $\mathbf{C} 4$ resin: $v$ varies from 2.8 to $3.4 \mathrm{~mm} / \mathrm{s}, P=0.4 \mathrm{~mW}\left(I=1.2 \mathrm{TW} / \mathrm{cm}^{2}\right)$ and $d_{x y}=0.25 \mu \mathrm{m}$ (lower row), $P=0.5 \mathrm{~mW}\left(I=1.5 \mathrm{TW} / \mathrm{cm}^{2}\right)$ and $d_{x y}=0.5 \mu \mathrm{m}$ (upper row). (b) Close-up of the $75 \times 75 \mu \mathrm{m}^{2}$ woodpile structure: $v=1 \mathrm{~mm} / \mathrm{s}, P=0.3 \mathrm{~mW}$ $\left(I=0.9 \mathrm{TW} / \mathrm{cm}^{2}\right), d_{x y}=0.25 \mu \mathrm{m}$. (c) Sculpture of Marvin out of C4 resin: $v=1.8 \mathrm{~mm} / \mathrm{s}, P=0.1 \mathrm{~mW}$ $\left(I=0.3 \mathrm{TW} / \mathrm{cm}^{2}\right), d_{x y}=0.25 \mu \mathrm{m}$. (d) Sculpture of Marvin out of AESO: $v=1.2 \mathrm{~mm} / \mathrm{s}, P=0.18 \mathrm{~mW}$ $\left(I=0.6 \mathrm{TW} / \mathrm{cm}^{2}\right), d_{x y}=0.25 \mu \mathrm{m}$. (e) Sculptures of Marvin out of $\mathbf{C} 4$ resin molded from the master structure (section (d)) via microtransfer molding; $365 \mathrm{~nm}$ wavelength light source was used for curing. Objects in sections (a) and (b) were manufactured with $20 \times 0.8$ NA objective, (c) and (d) $63 \times 1.4$ NA. All SEM images were obtained at $45^{\circ}$ angle.

Produced objects corresponded to the used 3D model, however with deviations including tilted columns and not fully formed logs. These could happen due to the too low degree of cross-linking, which causes shrinkage, when $d_{x y} 0.5 \mu \mathrm{m}$ was applied. Also, the voids on the woodpile's surfaces were observed. The voids were caused by bubbles, which have appeared due to the inhomogeneity of the resin, resulting in the deviation of the optical damage threshold through the whole material. Thus, in exposing resin $\mathrm{C} 4$ with tightly focused laser irradiation, some parts were over-exposed and induced bubble formation. Using a higher numerical aperture objective, a sculpture of Marvin was produced (Figure 9c). The basic shape of the given STL model was polymerized, but detailed parts of the face, ears, and the loop were missing. To obtain a well-defined Marvin out of C4 resin, a $\mu \mathrm{TM}$ 
technique was employed. A master structure of Marvin was produced out of AESO (Figure 9d). The replicated structures of Marvin were manufactured by curing the $\mathbf{C} 4$ resin inside a PDMS mold with UV diode. The obtained objects are demonstrated in Figure 9e. In this case, the produced Marvin had a smooth surface and detailed parts, except loops, which were not replicated due to the limited capability of the $\mu \mathrm{TM}$ technique to replicate closed loops. Differences in material surface appearance emerged because of the different illumination conditions. Using DLW, objects were made of stitched scanning point-by-point manner and thresholded light-matter interaction, sensitive to the material's inhomogeneity. On the other hand, with $\mu \mathrm{TM}$ a uniform UV irradiation distribution resulted in homogeneous curing.

\section{Conclusions}

Novel vanillin acrylate-based resins were designed and investigated as candidate materials for optical 3D printing. The kinetics of photocross-linking of vanillin dimethacrylate or vanillin diacrylate using ethyl(2,4,6-trimethylbenzoyl)phenylphosphinate as photoinitiator were investigated by real-time photorheometry. The photocross-linking of the vanillin dimethacrylate-based resins was faster compared with the vanillin diacrylate-based resins. The gel point was reached the fastest when 3 mol.\% of photoinitiator was used. The addition of solvent into the resin slowed down the photocross-linking process, and less-rigid polymers were obtained. The vanillin diacrylate-based polymer prepared without solvent possessed higher values of yield of insoluble fraction, thermal stability, and lower swelling values in comparison to the vanillin dimethacrylate-based polymer. Only the vanillin diacrylate-based polymer prepared without solvent was appropriate for testing of mechanical properties. It demonstrated similar properties to those of the commercially available photocurable resins. Subsequently, the possibility to optically structure this resin was successfully demonstrated. Although acquisition of a smooth surface of the structures proved to be challenging when employing DLW 3D lithography due to material inhomogeneity, the microtransfer molding technique allowed to overcome this limitation. For the improvement of the mechanical properties of other polymers, the addition of reactive diluents will be carried out in further studies. Vanillin diacrylate polymer film showed a significant antimicrobial effect only a bit weaker than that of chitosan film.

Author Contributions: J.O., A.N. and S.K. conceived and designed the experiments and analyzed the data; A.N. performed all experiments and characterizations, except the E.S. part; E.S. performed direct laser writing 3D lithography and replication experiments and characterized microstructures; E.S., S.R., and M.M. conceived the experimental plan and interpreted the optical 3D printing results; V.R. and D.B. designed and performed experiments and characterized the antimicrobial activity; all authors contributed to writing the manuscript. All authors have read and agreed to the published version of the manuscript.

Acknowledgments: This research was funded by the European Social Fund under the measure No. 09.3.3-LMT-K-712 "Development of Competences of Scientists, other Researchers and Students through Practical Research Activities" (grant agreement No. 09.3.3.-LMT-K-712-10-0161), EU ERDF, through the INTERREG BSR Programme (ECOLABNET project \#R077) and LASERLAB-EUROPE (grant agreement No. 871124, European Union's Horizon 2020 research and innovation programme).

Conflicts of Interest: The authors declare no conflicts of interest.

\section{References}

1. Liu, J.; Sun, L.; Xu, W.; Wang, Q.; Yu, S.; Sun, J. Current advances and future perspectives of 3D printing natural-derived biopolymers. Carbohydr. Polym. 2019, 207, 297-316. [CrossRef]

2. Li, N.; Huang, S.; Zhang, G.; Qin, R.; Liu, W.; Xiong, H.; Shi, G.; Blackburn, J. Progress in additive manufacturing on new materials: A review. J. Mater. Sci. Technol. 2019, 35, 242-269. [CrossRef]

3. Li, Y.; Zhong, J.; Wu, L.; Weng, Z.; Zheng, L.; Peng, S.; Zhang, X. High performance POSS filled nanocomposites prepared via UV-curing based on 3D stereolithography printing. Compos. Part A 2019, 117, 276-286. [CrossRef]

4. Dizon, J.R.C.; Espera, A.H., Jr.; Chen, Q.; Advincula, R.C. Mechanical characterization of 3D-printed polymers. Addit. Manuf. 2018, 20, 44-67. [CrossRef] 
5. Barner-Kowollik, C.; Bastmeyer, M.; Blasco, E.; Delaittre, G.; Muller, P.; Richter, B.; Wegener, M. 3D Laser micro- and nanoprinting: Challenges for chemistry. Angew. Chem. Int. Ed. 2017, 56, 15828-15845. [CrossRef] [PubMed]

6. Schift, H. Nanoimprint lithography: 2D or not 2D? A review. Appl. Phys. Part A 2015, 121, 415-435. [CrossRef]

7. Andrzejewska, E. Photopolymerization kinetics of multifunctional monomers. Prog. Polym. Sci. 2001, 26, 605-665. [CrossRef]

8. Sangermano, M.; Razza, N.; Crivello, J.V. Cationic UV-Curing: Technology and Applications. Macromol. Mater. Eng. 2014, 299, 775-793. [CrossRef]

9. Yagci, Y.; Jockusch, S.; Turro, N.J. Photoinitiated Polymerization: Advances, Challenges, and Opportunities. Macromolecules 2010, 43, 6245-6260. [CrossRef]

10. Wu, J.; Zhao, Z.; Hamel, C.M.; Mu, X.; Kuang, X.; Guo, Z.; Qi, H.J. Evolution of material properties during free radical photopolymerization. J. Mech. Phys. Solids. 2018, 112, 25-49. [CrossRef]

11. Kaur, M.; Srivastava, A.K. Photopolymerization: A Review. J. Macromol. Sci. Polymer. Rev. 2002, C42, 481-512. [CrossRef]

12. Green, W.A. Industrial Photoiniciators. A Technical Guide, 1st ed.; CRC Press: Boca Raton, FL, USA; Taylor and Francis Group: London, UK, 2001; ISBN 978-14-3982-745-1.

13. Fache, M.; Boutevin, B.; Caillol, S. Vanillin Production from Lignin and Its Use as a Renewable Chemical. Sustain. Chem. Eng. 2016, 4, 35-46. [CrossRef]

14. Yu, Q.; Peng, X.; Wang, Y.; Geng, H.; Xu, A.; Zhang, X.; Xu, W.; Ye, D. Vanillin-based degradable epoxy vitrimers: Reprocessability and mechanical properties study. Eur. Polym. J. 2019, 117, 55-63. [CrossRef]

15. Steinmetz, Z.; Kurtz, M.P.; Zubrod, J.P.; Meyer, A.H.; Elsner, M.; Schaumann, G.E. Biodegradation and photooxidation of phenolic compounds in soil-A compound-specific stable isotope approach. Chemosphere 2019, 230, 210-218. [CrossRef] [PubMed]

16. Wang, S.; Ma, S.; Xu, C.; Liu, Y.; Dai, J.; Wang, Z.; Liu, X.; Chen, J.; Shen, X.; Wei, J.; et al. Vanillin-Derived High-Performance Flame Retardant Epoxy Resins: Facile Synthesis and Properties. Macromolecules 2017, 50, 1892-1901. [CrossRef]

17. Fitzgerald, D.J.; Stratford, M.; Gasson, M.J.; Ueckert, J.; Bos, A.; Narbad, A. Mode of antimicrobial of vanillin against Escherichia coli, Lactobacillus plantarum and Listeria innocua. J. Appl. Microbiol. 2004, 97, 104-113. [CrossRef]

18. Salmi-Mani, H.; Terreros, G.; Barroca-Aubry, N.; Aymes-Chodur, C.; Regeard, C.; Roger, P. Poly(ethylene terephthalate) films modified by UV-induced surface graft polymerization of vanillin derived monomer for antibacterial activity. Eur. Polym. J. 2018, 103, 51-58. [CrossRef]

19. Licari, J.J.; Swanson, D.W. Adhesives Technology for Electronic Applications, 2nd ed.; Elsevier Science: Amsterdam, The Netherlands, 2011; ISBN 978-08-1551-600-2.

20. Lebedevaite, M.; Ostrauskaite, J.; Skliutas, E.; Malinauskas, M. Photoinitiator free Resins Composed of Plant-Derived Monomers for the Optical $\mu$-3D Printing of Thermosets. Polymers 2019, 11, 116. [CrossRef]

21. Danilevičius, P.; Rekšyte, S.; Balčiūnas, E.; Kraniauskas, A.; Širmenis, R.; Baltriukienè, D.; Bukelskienė, V.; Gadonas, R.; Sirvydis, V.; Piskarskas, A.; et al. Laser 3D micro/nanofabrication of polymers for tissue engineering applications. Opt. Laser Technol. 2013, 45, 518-524. [CrossRef]

22. Mezger, T.G. The Rheology Handbook, 3rd ed.; Vincentz Network: Hanover, Germany, 2011; ISBN 978-38-6630-864-0.

23. Candan, Z.; Gardner, D.J.; Shaler, S.M. Dynamic mechanical thermal analysis (DMTA) of cellulose nanofibril/nanoclay/pMDI nanocomposites. Compos. Part B 2016, 90, 126-132. [CrossRef]

24. Macarie, L.; Ilia, G. The influence of temperature and photoinitiator concentration on photoinitiated polymerization of diacrylate monomer. Cent. Eur. J. Chem. 2005, 3, 721-730. [CrossRef]

25. Valdebenito, A.; Encinas, M.V. Effect of solvent on the free radical polymerization of N,N-dimethylacrylamide. Polym. Int. 2010, 59, 1246-1251. [CrossRef]

26. Miyazaki, K.; Horibe, T. Polymerization of multifunctional methacrylates and acrylates. J. Biomed. Mater. Res. 1988, 22, 1011-1022. [CrossRef] [PubMed]

27. Shortall, A.C. How light source and product shade influence cure depth for a contemporary composite. J. Oral. Rehabil. 2005, 32, 906-911. [CrossRef] [PubMed] 
28. Ding, R.; Du, Y.; Goncalves, R.B.; Francis, L.F.; Reineke, T.M. Sustainable near UV-curable acrylates based on natural phenolics for stereolithography 3D printing. Polym. Chem. 2019, 10, 1067-1077. [CrossRef]

29. Benhabiles, M.S.; Salah, R.; Lounici, H.; Drouiche, N.; Goosen, M.F.A.; Mameri, N. Antibacterial activity of chitin, chitosan and its oligomers prepared from shrimp shell waste. Food Hydrocoll. 2012, 29, 48-56. [CrossRef]

30. Ngarmsak, M.; Delaquis, P.; Toivonen, P.; Ngarmsak, T.; Ooraikul, B.; Mazza, G. Antimicrobial activity of vanillin against spoilage microorganisms in stored fresh-cut mangoes. J. Food Prot. 2006, 69, 1724-1727. [CrossRef]

31. Ünver, H.; Cantürk, Z.; Özarda, M.G. Evaluation of antimicrobial effect against some microorganisms and apoptotic activity against Candida species of new vanillin derivatives. CBU J. Sci. 2019, 15, 87-94. [CrossRef]

C 2020 by the authors. Licensee MDPI, Basel, Switzerland. This article is an open access article distributed under the terms and conditions of the Creative Commons Attribution (CC BY) license (http://creativecommons.org/licenses/by/4.0/). 